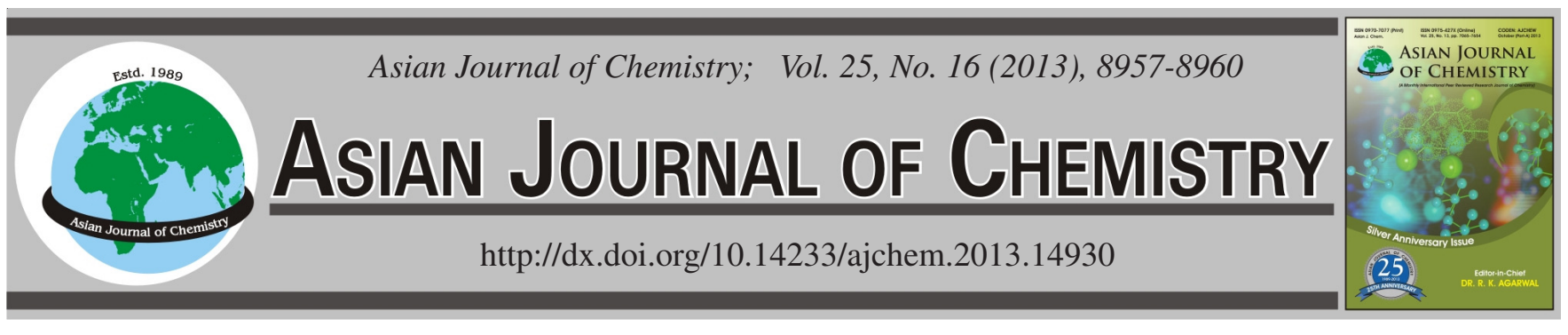

\title{
Distribution and Source Identification of Polycyclic Aromatic Hydrocarbons Residues in Different Types of Topsoil Collected from Jilin Province, China
}

\author{
Baolin Liu ${ }^{1,2}$, Ming Li ${ }^{1}$, XiuYi Hua ${ }^{1}$, Deming Dong ${ }^{1, *}$ and Weihua Dong ${ }^{2}$
}

${ }^{1}$ Key Laboratory of Groundwater Resources and Environment of Ministry of Education, College of Environment and Resources, Jilin University, Changchun 130012, P.R. China

${ }^{2}$ College of Chemistry, Changchun Normal University, Jilin 130032, Changchun Province, P.R. China

*Corresponding author: Fax: +86 431 84727678; Tel: +86 431 85168429; E-mail: dmdong@jlu.edu.cn

(Received: 8 December 2012;

Accepted: 11 September 2013)

AJC-14090

\begin{abstract}
Samples of top soils $(0-20 \mathrm{~cm})$ were collected in Jilin province in the northeast of China. The levels of 16 polycyclic aromatic hydrocarbons were analyzed by gas chromatography. In soils, the total content of 16 polycyclic aromatic hydrocarbons ranged between $67.1 \mathrm{ng} \mathrm{g}^{-1}$ to $27941.2 \mathrm{ng} \mathrm{g}^{-1}$ (dry weight) with arithmetic mean of $2190 \mathrm{ng} \mathrm{g}^{-1}$ for samples collected different types of soil. The polycyclic aromatic hydrocarbons composition of surface soil in Jilin Province, mainly in the 3 and 4 rings such as pyrene. The research shows that there was a strong pyrogenic influence on soil polycyclic aromatic hydrocarbons in all soils sampled in Jilin province. Some parts of the test results show that different molecular indices for phenanthrene/anthracene and fluoranthene/pyrene, respectively, indicates a possible influence of petrogenic inputs. Soil organic carbon is an important factor to affect distribution of polycyclic aromatic hydrocarbons in the soil samples. These results indicate that local sources of polycyclic aromatic hydrocarbons, especially different types of land, lead to very different values of polycyclic aromatic hydrocarbons.
\end{abstract}

Key Words: Soil, Polycyclic aromatic hydrocarbons, Organic carbon, Environmental evaluation.

\section{INTRODUCTION}

Polycyclic aromatic hydrocarbons is of concern to environmental scientists because of there persistence, bioaccumulatition and long-range atmospheric transport with the rapid development of agriculture and industry ${ }^{1-3}$. Polycyclic aromatic hydrocarbons have been detected in environment such as soils of China by many researchers ${ }^{4-9}$. Most of the reported studies focused on the central and south of China, however, such kind of studies focused on the northeast of China is lacking especially on the research of polycyclic aromatic hydrocarbons.

Polycyclic aromatic hydrocarbons are a group of chemical compounds including carcinogens and mutagens which are identified as priority pollutants by U.S. EPA. The main anthropogenic source of polycyclic aromatic hydrocarbons is the incomplete combustion of fossil fuel and biomass material. A mass of industrial activity such as petrochemical industrial practices, vehicular missions, power plant emissions and domestic heating create the main sources of polycyclic aromatic hydrocarbons.

The study region is in the northeast of China, including abundant farmland and also many industrial urban areas. The climate of Jilin province is typically cool monsoon weather with the annual average temperature of $8.2^{\circ} \mathrm{C}$ in October. There was very little study on polycyclic aromatic hydrocarbons residue levels in topsoil of Jilin province. The main objective of the study was to investigate the current status of residues for polycyclic aromatic hydrocarbons in topsoil from some farmland, industrial region and woodland, which gave the information about status of contamination. The results from this study can provide reasonable ways for further development and maintain a sustainable development in Jilin province of China.

\section{EXPERIMENTAL}

Sampling: Thirty-two topsoil $(0-20 \mathrm{~cm})$ samples were collected from six sites, of which twenty were dry farmland (DR), five were paddy field (PF), three were industrial park (IP) and four were wood land (WL), in October, 2011. The locations of these sites are shown in Fig. 1. The top 20-cm layer of soil was scooped using a stainless steel scoop that had been pre-washed by acetone. Each sub-sample was placed a prewashed glass flask with Teflon cap and transported to the laboratory then frozen and stored at $-20{ }^{\circ} \mathrm{C}$ until further analysis.

Analysis: Details of analysis of soil samples are reported elsewhere ${ }^{10}$. The samples were accurately weighed, homogenized and quantitatively transferred into pre-cleaned 


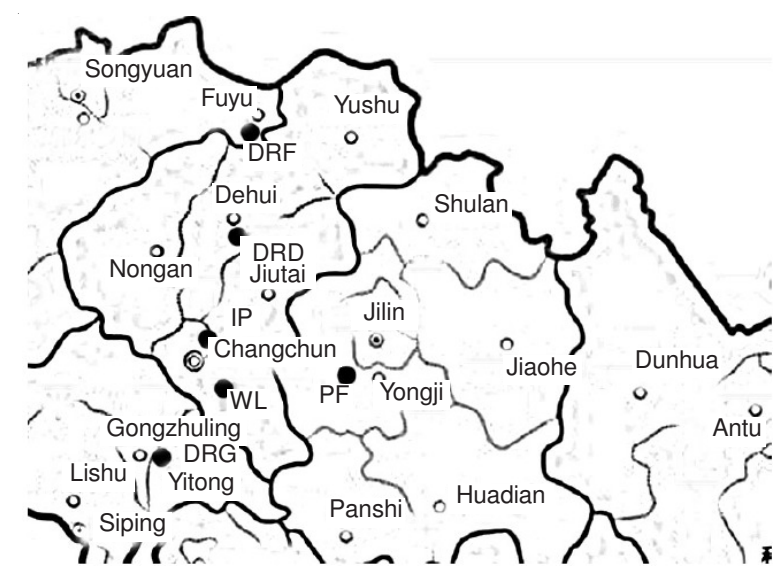

Fig. 1. Location of sampling sites DRF: Fuyu dry farmland; DRD: Dehui dry farmland; IP: Changchun industrial park; WL: Changchun wood land; DRG: Gongzhuling dry farmland; PF: Yongji paddy field

centrifuge tubes. The soil samples were Soxhlet extracted with $180 \mathrm{~mL}$ dichloromethane for polycyclic aromatic hydrocarbons. The exact samples were subjected to multilayer silica/alumina column for fractionation after concentrated and then $15 \mathrm{~mL}$ hexane was applied to elute the column. The second half is that target contaminants were eluted with $70 \mathrm{~mL}$ of dichloromethane and hexane (v/v, 30:70) and then the products were concentrated by a gentle flow of high-purity nitrogen to appropriate volumes.
Identification and quantification of the samples were performed on an Agilent gas chromatograph system with a HP-5 capillary column $(60 \mathrm{~m} \times 0.25 \mathrm{~mm}$ i.d $\times 0.25 \mu \mathrm{m}$ film thickness $)$ operating in selective ion monitoring (SIM) mode. Splitless injection of $1 \mu \mathrm{L}$ of sample was conducted with an auto sampler. Helium was used as carrier gas. For polycyclic aromatic hydrocarbons, oven was programmed from $90{ }^{\circ} \mathrm{C}$ (held for $2 \mathrm{~min}$ ) initially to $200{ }^{\circ} \mathrm{C}$ (held for $5 \mathrm{~min}$ ) at a rate of $10^{\circ} \mathrm{C} /$ min and then to $300{ }^{\circ} \mathrm{C}$ (held for $15 \mathrm{~min}$ ) at a rate of $3{ }^{\circ} \mathrm{C} / \mathrm{min}$. The injector temperature was held at $290^{\circ} \mathrm{C}$ and the detector temperature was $310^{\circ} \mathrm{C}$. The calibration curves were made from standard solutions at six concentration levels for quantification.

Quality assurance/quality control: The limit of detection, defined as 3:1 signal-to-noise value $(\mathrm{S} / \mathrm{N})$, ranged from 0.004 to $0.12 \mathrm{ng} / \mathrm{g} \mathrm{dw}$ for polycyclic aromatic hydrocarbons. The average surrogate standard recoveries ranged from $64.5 \%$ to $104.6 \%$ except for phenanthrene $(46.8 \% \pm 21.5 \%)$. Blank were determined by soxhlet extracting a thimble padded clean sodium sulfate and treating the extract as a sample. Due to all the blank values were below the quantification limits, all the polycyclic aromatic hydrocarbons data were not corrected by surrogate recovery and blank.

\section{RESULTS AND DISCUSSION}

Soil concentrations of polycyclic aromatic hydrocarbons: A wide range of soil polycyclic aromatic hydrocarbons concen-

\begin{tabular}{|c|c|c|c|c|c|c|}
\hline \multicolumn{7}{|c|}{$\begin{array}{c}\text { TABLE-1 } \\
\text { INFORMATION OF SAMPLING SITES }\end{array}$} \\
\hline Code & Land use & Total PAHs (ng/g) & Phe/Ant index & Flu/Pyr index & $\mathrm{SOC}(\%)$ & Dominant origin \\
\hline IP1 & Industrial park & 21039.9 & 1.2 & 8.4 & 7.67 & Pyro $^{a}$ and Petro \\
\hline IP2 & Industrial park & 27941.2 & 0.6 & 6.3 & 7.38 & Pyro \\
\hline IP3 & Industrial park & 513.4 & 0.5 & 0.06 & 3.03 & Pyro and Petro \\
\hline WL1 & Wood land & 67.1 & 1.1 & 0.07 & 1.12 & Pyro and Petro \\
\hline WL2 & Wood land & 593.2 & 2.7 & 0.008 & 1.19 & Pyro and Petro \\
\hline WL3 & Wood land & 300.3 & 0.4 & 1.3 & 1.10 & Pyro \\
\hline WL4 & Wood land & 469.3 & 0.5 & ND & 0.93 & Pyro \\
\hline PF1 & Paddy field & 766.7 & 2.1 & 3.0 & 2.21 & Pyro \\
\hline PF2 & Paddy field & 566.7 & 0.9 & 0.01 & 1.83 & Pyro and Petro \\
\hline PF3 & Paddy field & 844.8 & 2.0 & 2.2 & 2.27 & Pyro \\
\hline PF4 & Paddy field & 817.9 & 0.3 & 3.1 & 2.55 & Pyro \\
\hline PF5 & Paddy field & 301.2 & 0.6 & 3.9 & 1.75 & Pyro \\
\hline DRD1 & Dry farmland & 833.5 & 9.6 & ND & 1.26 & Pyro \\
\hline DRD2 & Dry farmland & 702.7 & 0.5 & 7.4 & 1.33 & Pyro \\
\hline DRD3 & Dry farmland & 921.8 & 0.6 & 0.02 & 1.22 & Pyro and Petro \\
\hline DRD4 & Dry farmland & 1634.5 & 1.3 & 0.08 & 0.02 & Pyro and Petro \\
\hline DRD5 & Dry farmland & 279.9 & 1.0 & 2.4 & 1.17 & Pyro \\
\hline DRD6 & Dry farmland & 1592.9 & 1.8 & 1.3 & 0.04 & Pyro \\
\hline DRG1 & Dry farmland & 2207.0 & 0.6 & 0.4 & 1.72 & Pyro and Petro \\
\hline DRG2 & Dry farmland & 342.2 & 0.6 & 1.8 & 1.34 & Pyro \\
\hline DRG3 & Dry farmland & 610.2 & 0.7 & 0.3 & 1.45 & Pyro and Petro \\
\hline DRG4 & Dry farmland & 1339.0 & 1.6 & 1.8 & 1.31 & Pyro \\
\hline DRG5 & Dry farmland & 176.9 & 1.0 & 0.8 & 2.23 & Pyro and Petro \\
\hline DRG6 & Dry farmland & 871.1 & 1.3 & 0.6 & 1.69 & Pyro and Petro \\
\hline DRF1 & Dry farmland & 79.9 & 4.3 & ND & 1.11 & Pyro \\
\hline DRF2 & Dry farmland & 492.7 & $\mathrm{ND}$ & 0.01 & 1.17 & Petro \\
\hline DRF3 & Dry farmland & 234.3 & 78.8 & ND & 1.12 & Petro \\
\hline DRF4 & Dry farmland & 169.7 & 1.4 & 2.8 & 1.25 & Pyro \\
\hline DRF5 & Dry farmland & 1890.7 & 0.6 & ND & 1.12 & Pyro \\
\hline DRF6 & Dry farmland & 403.7 & 1.6 & 12.9 & 1.07 & Pyro \\
\hline DRF7 & Dry farmland & 637.7 & 1.0 & 0.002 & 1.06 & Pyro and Petro \\
\hline DRF8 & Dry farmland & 446.6 & 1.2 & 0.8 & 0.90 & Pyro and Petro \\
\hline
\end{tabular}


TANLE-2

SOME PUBLISHED SOIL ENVIRONMENTAL STANDARDS FOR POLY AROMATIC HYDROCARBONS IN SOILS $\left(\mu \mathrm{g} \mathrm{g} \mathrm{g}^{-1}\right)$

\begin{tabular}{|c|c|c|c|c|c|c|c|c|c|c|c|c|c|}
\hline Compound name & $\begin{array}{c}\text { RIVM } \\
\text { TV } \\
\end{array}$ & $\begin{array}{l}\mathrm{BC} \\
\mathrm{Ag}\end{array}$ & $\begin{array}{l}\text { BC } \\
\text { UP }\end{array}$ & $\begin{array}{c}\mathrm{BC} \\
\mathrm{R}\end{array}$ & $\begin{array}{c}\mathrm{BC} \\
\mathrm{C} \\
\end{array}$ & $\begin{array}{c}\mathrm{BC} \\
\mathrm{I} \\
\end{array}$ & $\begin{array}{c}\mathrm{CCME} \\
\mathrm{Ag}\end{array}$ & $\begin{array}{c}\text { CCME } \\
\text { RP }\end{array}$ & $\begin{array}{c}\text { CCME } \\
\mathrm{C}\end{array}$ & $\begin{array}{c}\text { CCME } \\
\text { I }\end{array}$ & $\begin{array}{c}\text { Ont } \\
\mathrm{Ag}(\mathrm{C}) \\
\end{array}$ & $\begin{array}{c}\text { Ont } \\
\mathrm{RP}(\mathrm{C})\end{array}$ & $\begin{array}{c}\text { Ont } \\
\text { IC (C) }\end{array}$ \\
\hline Acenaphthene & & & & & & & & & & & 15 & 15 & 15 \\
\hline Acenaphthylene & & & & & & & & & & & 100 & 100 & 100 \\
\hline Anthracene & & & & & & & & & & & 28 & 28 & 28 \\
\hline Benzo(a)anthracene & & 0.1 & 1 & 1 & 10 & 10 & 0.1 & 1 & 10 & 10 & 6.6 & 6.6 & 6.6 \\
\hline Benzo(a)pyrene & & & & & & & 0.1 & 0.7 & 0.7 & 0.7 & 1.2 & 1.2 & 1.9 \\
\hline Benzo(b)fluoranthene & & 0.1 & 1 & 1 & 10 & 10 & 0.1 & 1 & 10 & 10 & 12 & 12 & 12 \\
\hline Benzo(ghi)perylene & & & & & & & & & & & 12 & 12 & 12 \\
\hline Chrysene & & & & & & & & & & & 12 & 12 & 17 \\
\hline Dibenz(ah)anthracene & & 0.1 & 1 & 1 & 10 & 10 & 0.1 & 1 & 10 & 10 & 1.2 & 1.2 & 1.9 \\
\hline Fluoranthene & & & & & & & & & & & 40 & 40 & 40 \\
\hline Fluorene & & & & & & & & & & & 340 & 340 & 340 \\
\hline Indeno(123-cd)pyrene & & 0.1 & 1 & 1 & 10 & 10 & 0.1 & 1 & 10 & 10 & 12 & 12 & 19 \\
\hline Naphthalene & & 0.1 & 5 & 5 & 50 & 50 & 0.1 & 0.6 & 22 & 22 & 4.6 & 4.6 & 4.6 \\
\hline Phenanthrene & & 0.1 & 5 & 5 & 50 & 50 & 0.1 & 5 & 50 & 50 & 40 & 40 & 40 \\
\hline Pyrene & & 0.1 & 10 & 10 & 100 & 100 & 0.1 & 10 & 100 & 100 & 250 & 250 & 250 \\
\hline PAH (total of 10$)^{\mathrm{a}}$ & 1 & & & & & & & & & & & & \\
\hline
\end{tabular}

Abbreviations: BC Ag: British Columbia Agricultural; BC UP: British Columbia Urban Park; BC R: British Columbia Residential; BC C: British Columbia; Commercial; BC I: British Columbia Industrial; CCME Ag: Canadian Council of Ministers of the Environment Agricultural; CCME RP: Canadian Council of; Ministers of the Environment Residential/Parkland; CCME C: Canadian Council of Ministers of the Environment Commercial; CCME I: Canadian Council of Ministers of the Environment Industrial; Ont Ag (C): Ontario Agricultural land use (coarse-Ag/g); Ont RP (C): Ontario Residential/Parkland land use (coarse-Ag/g); Ont IC (C): Ontario Industrial/Commercial land use (coarse-Ag/g); RIVM TV: The Netherlands soil/sediment (mg/kg dry material) target value. ${ }^{\text {TT }}$ The total of anthracene, benzo(a)anthracene, benzo(k)fluoroanthene, benzo(a)pyrene, chrysene, phenanthrene, fluoroanthene, indeno(123-cd)pyrene, naphthalene and benzo(ghi)perylene

trations were given in Table-1, which included those polycyclic aromatic hydrocarbons considered as carcinogens by the US Environmental Protection Agency. The concentrations of polycyclic aromatic hydrocarbons varied from $67.1 \mathrm{ng} \mathrm{g}^{-1}$ to $27941.2 \mathrm{ng} \mathrm{g}^{-1}$ (dry weight) with arithmetic mean of $2190 \mathrm{ng}$ $\mathrm{g}^{-1}$. The highest pollution levels were observed for soil samples at IP-1 (21039.9 $\left.\mathrm{ng} \mathrm{g}^{-1}\right)$ and IP-2 (27941.2 $\left.\mathrm{ng} \mathrm{g}^{-1}\right)$. The high pollution levels are significantly higher than values reported on in the soil along with the north costal area of the Bohai Sea (66.3 $\mathrm{ng} \mathrm{g}^{-1}$ to $\left.920.4 \mathrm{ng} \mathrm{g}^{-1}\right)^{11}$, however, the pollution of the industrial park are comparable with the found in an abandoned coking Factory in Beijing (672.8 $\mathrm{ng} \mathrm{g}^{-1}$ to $\left.144814.3 \mathrm{ng} \mathrm{g}^{-1}\right)^{12}$. A wide range of molecular weights of polycyclic aromatic hydrocarbons are discovered in the soils collected, from naphthalene to benzo(ghi)perylene. The variation in percentages of polycyclic aromatic hydrocarbon compounds with different ring numbers in soils were showed in Fig. 2. The figure shows that the polycyclic aromatic hydrocarbons composition

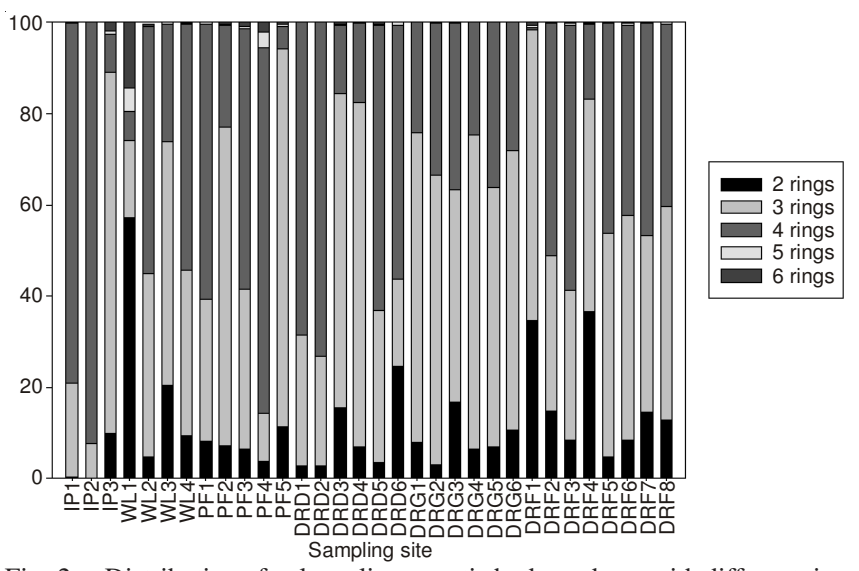

Fig. 2. Distribution of polycyclic aromatic hydrocarbons with different ring numbers in different soil samples collected from areas of Jilin province, China of surface soil in Jilin Province, mainly in the 3 and 4 rings such as pyrene. However, the concentrations of polycyclic aromatic hydrocarbons with 5 rings and 6 rings were relatively low in most soil samples.

Some countries have announced polycyclic aromatic hydrocarbons in environmental standards which were shown in Table-2. polycyclic aromatic hydrocarbons in about $19 \%$ of the soil samples exceed the standards published in the Netherlands, indicating their potential risk to human health. Currently China has not developed the allowable concentration of the soil of polycyclic aromatic hydrocarbons, but the provisions of the sludge from agricultural use of the maximum allowable content of $3 \mathrm{mg} / \mathrm{kg}$ (GB4284-84). The concentration of each sample point was within this range.

Source analysis of polycyclic aromatic hydrocarbons. Sources of polycyclic aromatic hydrocarbons in the environment is very complex, incomplete combustion of fossil fuels at high temperatures, the slow oxidation of organic matter in the geochemical and digenetic processes of polycyclic aromatic hydrocarbons can be released to the environment ${ }^{13}$. The relative abundance of the number of rings in polycyclic aromatic hydrocarbons may reflect the sources of pollution are the combustion of fossil fuels and plant materials or natural digenesis. Usually high molecular weight within 4 rings and more of polycyclic aromatic hydrocarbons is mainly from the high temperature combustion of fossil fuels and low molecular weight within 2 rings and 3 rings of polycyclic aromatic hydrocarbons is from natural digenesis. The ratios of phenanthrene/anthracene (Phe/Ant) within the 3-ring polycyclic aromatic hydrocarbons group and fluoranthene/pyrene (Flu/ Pyr) within the 4-ring polycyclic aromatic hydrocarbons group were used to form molecular indices ${ }^{14,15}$. Usually, Phe/Ant ratio $<10$ and Flu/Pyr ratio $>1$ indicate that polycyclic aromatic hydrocarbons come from pyrogenic source and Phe/Ant $>15$ 
and Flu/Pyr $<1$ indicate petrogenic origins of polycyclic aromatic hydrocarbons ${ }^{15}$. The ratios of Phe/Ant and Flu/Pyr are listed in Table-1. The Flu/Pyr ratios in all samples ranged from 0.01 to 12.9 and Phe/Ant ratios ranged from 0.4 to 78.8 . It can be seen that there was a strong pyrogenic influence on soil polycyclic aromatic hydrocarbons in all soils sampled in Jilin province. Some parts of the test results show that different molecular indices for Phe/Ant and Flu/Pyr, respectively, indicates a possible influence of petrogenic inputs.

Relationship of concentrations of polycyclic aromatic hydrocarbons and soil organic carbon: Modern research has shown a very close relationship between polycyclic aromatic hydrocarbons and soil matrix ${ }^{16,17}$. Soil organic carbon varied greatly between soil samples ranging from $0.02 \%$ to $7.67 \%$ with a mean of $1.77 \%$ (Table-1). The results of correlation analysis can be shown in Fig. 3. The Results can be expressed by the following equation:

$$
\Sigma \text { PAHs }=3289.35 \text { SOC }-3268.80, \mathrm{n}=32, \mathrm{r}^{2}=0.81
$$

The correlation analysis showed that both were correlated significantly $(r=0.81)$ on the confidence level of $p=0.05$, illustrating that soil organic carbon is an important factor to affect distribution of polycyclic aromatic hydrocarbons in the soil samples. Polycyclic aromatic hydrocarbons are hydrophobic, high lipophilicity and high octanol-water partition coefficient of the special, so their contents depend on soil organic content.

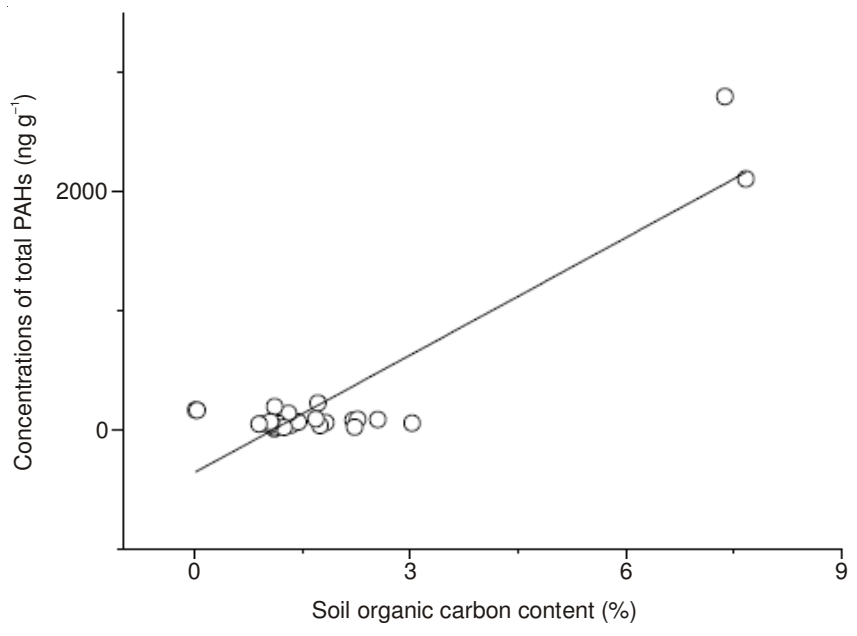

Fig. 3. Relationship between soil organic carbon and total concentrations of polycyclic aromatic hydrocarbons in soil samples at different locations in Jilin province

\section{Conclusion}

The total amount of polycyclic aromatic hydrocarbons in the soil of different regions in Jilin Province vary from 67.1 $\mathrm{ng} \mathrm{g}^{-1}$ to $27941.2 \mathrm{ng} \mathrm{g}^{-1}$. Based on the molecular indices (phenanthrene/anthracene and fluoranthene/pyrene ratios) of polycyclic aromatic hydrocarbons in soils, it was indicated that the main source of polycyclic aromatic hydrocarbons in the soil of some areas in Jilin Province was the pyrogenic source. Polycyclic aromatic hydrocarbons with 2-4 rings were the major fractions of the total soil polycyclic aromatic hydrocarbons. Soil organic carbon is an important factor to affect distribution of polycyclic aromatic hydrocarbons in the soils.

ACKNOWLEDGEMENTS

The authors thank the project supported by Natural Science Foundation of Changchun Normal University, The National Natural Science Foundation (No. 31200407) and Specialized Research Fund for the Doctoral Program of Higher Education (No. 20100061110041)

\section{REFERENCES}

1. T.Y. Wang, Y.L. Lu, H. Zhang and Y.J. Shi, Environ. Int., 31, 813 (2005).

2. E. Dewailly, P. Ayotte, S. Bruneau, S. Gingras, M. Belles-Isles and R. Roy, Environ. Health Perspect., 108, 205 (2006).

3. S. Tao, Y. Yang, H.Y. Cao, W.X. Liu, R.M. Coveney and F.L. Xu, Environ. Pollut., 139, 183 (2006).

4. Y. Chen, C. Wang and Z. Wang, Environ. Int., 31, 778 (2005).

5. J. Gao, Y. Luo, Q. Li, H. Zhang, L. Wu, J. Song, W. Qian, P. Christie and S.M. Chen, Environ. Geochem. Health, 28, 79 (2006).

6. F. Gao, J. Jia and X. Wang, Arch. Environ. Contaminat. Toxicol., 54, 155 (2008)

7. Y.-H. Zhang, J.-L. Li, T.-L. Miu and Z.-W. Luo, Asian J. Chem., 25, 6521 (2013).

8. X. Li, Y. Zhu, X. Liu, S. Fu, X. Xu and H. Cheng, Arch. Environ. Contaminat. Toxicol., 51, 329 (2006).

9. Y. Shi, F. Meng, F. Guo, Y. Lu, T. Wang and H. Zhang, Arch. Environ. Contaminat. Toxicol., 49, 37 (2005).

10. B.X. Mai, H.M. Fu, G.Y. Sheng, Y.H. Kang, Z. Lin, G. Zhang, Y.-S. Min and E.Y. Zeng, Environ. Pollut., 117, 457 (2002).

11. W.T. Jiao, T.Y. Wang, Y.L. Lu, W. Luo and W.Y. Hu, Asian J. Ecotoxicol., 5, 193 (2010)

12. Y. Feng, Y.L. Lu, W.T. Jiao, T.Y. Wang, G. Wang, Y.J. Shi and W. Luo, Asian J. Ecotoxicol., 4, 399 (2009).

13. H.H. Soclo, P.H. Garrigues and M. Ewald, Marine Pollut. Bull., 40, 387 (2000).

14. J.C. Colombo, E. Pelletier, C. Brochu and M. Khalil, Environ. Sci. Technol., 23, 888 (1989).

15. P. Baumard, H. Budzinski, Q. Michon, P. Garrigues, T. Burgeot, Estuar Coast Shelf Sci., 47, 77 (1998).

16. N. Chung and M. Alexander, Environ. Sci. Technol., 32, 855 (1998).

17. N. Chung and M. Alexander, Chemosphere, 48, 109 (2002). 